\title{
İstilacı balık türü Pseudorasbora parva (Temminck ve Schlegel, 1846) Çakıl Balığı'nın Gökçeada (Çanakkale)'dan ilk kaydı
}

\section{First record for invasive Topmouth gudgeon Pseudorasbora parva (Temminck and Schlegel, 1846) from Gökçeada (Çanakkale)}

\author{
İlker Bakaç* (1) • Şükran Yalçın Özdilek² • F. Güler Ekmekçi \\ ${ }^{1}$ Çanakkale Onsekiz Mart Üniversitesi, Fen Bilimleri Enstitüsü, Terzioğlu Yerleşkesi, 17100 Çanakkale, Türkiye \\ ${ }^{2}$ Çanakkale Onsekiz Mart Üniversitesi, Fen Edebiyat Fakültesi Terzioğlu Yerleșkesi, 17100 Canakkale, Türkiye \\ ${ }^{3}$ Hacettepe Üniversitesi, Fen Fakültesi Biyoloji Bölümü Beytepe Yerleşkesi, 06100 Ankara, Türkiye \\ *Corresponding author. ilkerbakac@gmail.com
}

\section{How to cite this paper:}

Bakaç, I.., Yalçın Özdilek, Ş. \& Ekmekçi, F.G. (2017). First record for invasive Topmouth gudgeon Pseudorasbora parva (Temminck and Schlegel, 1846) from Gökçeada (Çanakkale). Ege Journal of Fisheries and Aquatic Sciences, 34(4):459-462. doi: 10.12714/egejfas.2017.34.4.14

Öz: Çanakkale ilinde yürütülen Biyolojik Çeşitllikik ve Envanter Tarama çalışmaları kapsamında 08.06.2016 tarihinde yapılan arazi çalışmasında Ege denizindeki adalarda ilk kez Gökçeada rezervuarda Pseudorasbora parva'ya rastlanmıştır. Deniz bariyerine karşın Gökçeada'da bu türün bulunması, istilacı türlerin insan etkisiyle yayılış alanının genişlemesinin çok açık bir kanıııdır. Türkiye iç sularına kolay adapte olan ve hızlı bir şekilde yayılış gösteren bu istilacı türün morfometrik ölçümleri alınmış ve Ege adaları için ilk kez kayıt olarak rapor edilmiştir.

Anahtar kelimeler: İstilacı balık türü, Ege adaları, balıklandırma, Gökçeada rezervuarı

Abstract: Pseudorasbora parva was found in the Gökçeada Reservoir in the field study within the scope of the Biodiversity and Inventory Screening studies carried out in Çanakkale, conducted on 08.06.2016. Despite the sea barrier, the presence of this species in Gökçeada is a very clear evidence of the expansion of the invasive species by anthropogenic effects. Morphometric measurements of this invasive species, which is easy to adapt to the inland waters and spread rapidly, was made and it was reported that this species firstly existed in Aegean islands.

Keywords: Invasive Fish Species, Aegean islands, Fish stocking, Gökçeada reservoir

\section{Gíriş}

Türkiye tatısuları balık biyoçeşitliliği bakımından zengin bir fauna'ya sahiptir (Atalay ve Toslak, 2013; Freyhof vd., 2014; Çiçek vd., 2015). Tatlısu kaynaklarına yapılan su kanalları, barajlar, arıtımadan suya verilen evsel atıklar, aşırı avcılık, su kaynağında doğal olarak bulunmayan balıkların aşılanması doğal fauna üzerinde tahribe neden olmaktadır. Bu bahsedilen faaliyetler tatısu kaynağında doğal olarak bulunan balık türlerinin beslenmesi, üremesi ve neslini devam ettirebilmesindeki olumsuz etkiyi arttırmakta ya popülasyonda azalmaya ya da neslin devamlılığının sağlanamamasına neden olmaktadır (Ekmekçi vd., 2013).

Tatlısu kaynağında inceleme yapmadan kontrolsüzce yapılan yabancı balık aşılamaları bulundukları bölgede istilacı olabilmektedir. Kontrolsüzce yapılan balık aşılamalarının doğal türler üzerindeki rekabet, habitat değiştirme, predatörlük, hibridizasyon, parazitlik ve hastalıklar gibi olumsuz etkileri olabileceği bilinmektedir (Ekmekçi ve Kırankaya, 2006).
Pseudorasbora parva (Temminck ve Schlegel, 1846) istilacı balık türünün yayılış alanı Uzak Doğu Asya'dır (Banarescu,1999). Zengin tatlı su ihtiyofaunasına sahip olan Türkiye sularında yayılan bu istilacı balık türü ortamda bulunan doğal balık türleri için tehdit oluşturmaktadır (Polat vd., 2011). Bu tehdit bu balığın taşımış olduğu parazitin de benzer şekilde hızlı yayılmasıyla da kendini göstermektedir (Ercan vd., 2015). Bu istilacı balık türüne Türkiye'de ilk kez 1982 yılında Trakya bölgesinde rastlanılmıştır (Erk'akan,1984). Bulunduğu bölgeye kısa sürede uyum sağlayan, yayılmacı ve istilacı bir tutum sergileyen bu balık hızlı bir şekilde Türkiye'nin pekçok tatısu havzasına yayılmıştır (Çetinkaya 2006, Ekmekçi vd., 2013). Ancak Çanakkale ili tatlısu kaynakları ile Gökçeada bölgesine dair böyle bir kayda rastlanmamıştır. Bu çalışmada Gökçeada'da kaydedilen $P$. parva istilacı türünün varlığı, yakalanan bireylere ait bazı morfometrik ve meristik özellikleri belirlenmiştir. Anadolu'nun yakın su havzalarına av araçlarının taşınması veya canlı balık aşılamaları esnasında giriş yaptığı 
düşünülen bu türün Gökçeada'ya muhtemel giriş yolları da irdelenecektir.

\section{MATERYAL VE METOT}

2014-2016 yılları arasında Çanakkale ilinde yürütülen Biyolojik Çeşitlilik ve Envanter Tarama çalışmaları kapsamında Gökçeada'da bulunan Gökçeada barajı girişinde 08 Haziran 2016 tarihinde "Samus-725MS"markalı elektroşoker cihazı ile 200 m uzunluğunda, $10 \mathrm{~m}$ genişlik ve yaklaşık $20 \mathrm{~cm}$ derinliğe sahip bir kesimde örnekleme yapılmıştır. Örnekleme bölgesinin haritası Şekil 1'de verilmiştir.

Örnekleme yapılan kesimde su sıcaklığı $18,6{ }^{\circ} \mathrm{C}$ olarak ölçülmüştür. Yakalanan balıklar \%4'lük formaldehit içerisine konulup fikse edilmiş ve teşhis edilmesi için laboratuvar ortamına getirilmiştir. Örneklerin teşhisinde ve ölçümlerin de), Kottelat ve Freyhof (2007) tarafından verilen karakterler esas alınmıştır.

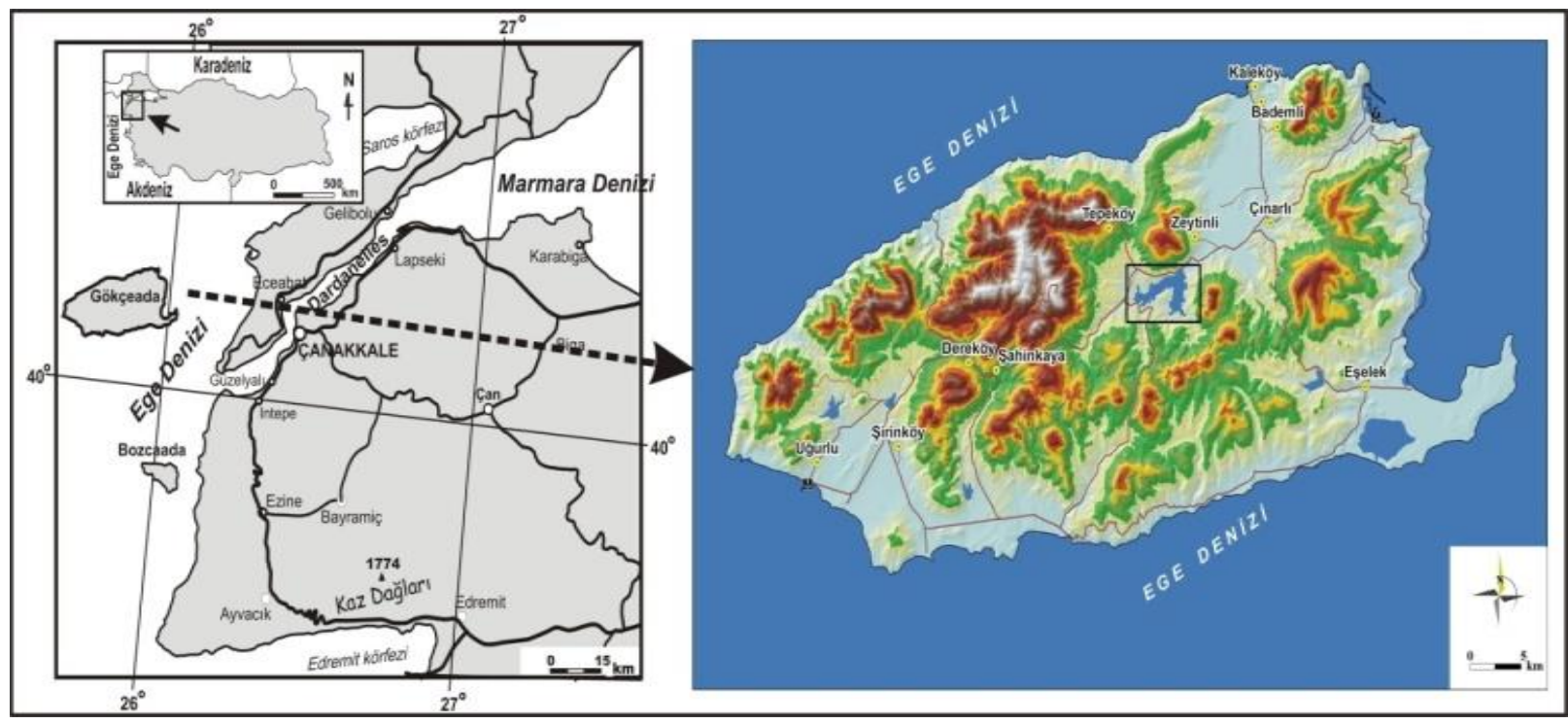

Şekil 1. Gökçeada bölgesi örnekleme yapılan alan

Figure 1. Sampling area in Gökçeada

\section{BULGULAR VE TARTIŞMA}

Gökçeada rezervuarında kısa süreli arazi çalışması sırasında göle giren akarsuyun ağız bölgesinde kıyıdan avlama yapılabilmiş, 5-6 bireylik gruplar halinde dolaşan $P$. parva'dan, 3 birey yakalanabilmiştir. Gökçeada rezervuarında taranan alan boyunca başka balık türü yakalanmamıştır. Yakalanan bireylerin metrik özellikleri Tablo 1'de ve örneklerden birinin fotoğrafı Şekil 2'de gösterilmiştir.

Pseudorasbora parva (Temminck \& Schlegel, 1846)

Diagnostik özellikleri: Dorsal yüzgeç ışın sayısı: III 8 Anal yüzgeç ışın sayısı: III 6 pektoral yüzgeç ışın sayısı: I, 10-11 ventral yüzgeç ışın sayısı: I, 7 yanal çizgideki pul sayısı: 36-37 Farinks dişleri: 5-5.

Cyprinidae familyasına ait olan bu türün vücudu sırt bölgesinde hafif kubbemsi görünüş kazanmıştır. Başın hemen arkasından başlayıp kuyruğa kadar uzanan siyah bant en belirgin özelliğidir. Ağız yukarıya doğru dönük, küçük ve çevresinde bıyık bulunmaz. Kuyruk yüzgeci çatallanması fazladır. Ürme döneminde erkeklerde kafa bölgesinde birçok sazangilde olduğu gibi küçük tüberküllere rastlanır. Ayrıca bu dönemde erkeklerde pulların dış kısmındaki pigmentasyon daha koyu bir renk alarak dişilere göre pulların dış sınırları daha belirgin bir şekilde görülür.

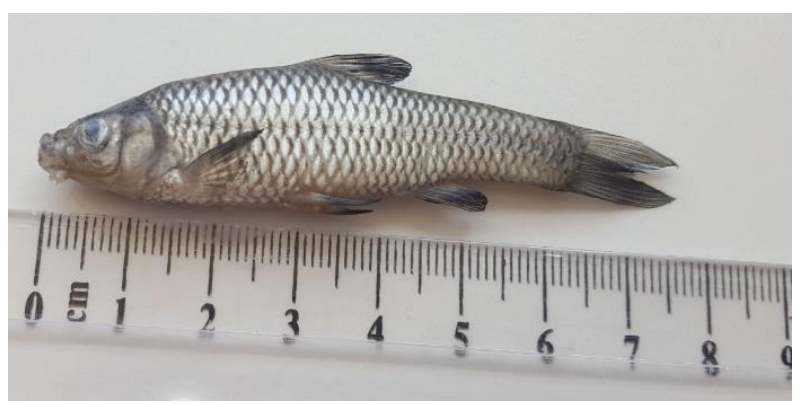

Şekil 2. P. parva örneğinin fotoğrafı (erkek birey)

Figure 2. The photo of $P$. parva specimen (a male specimen)

Gökçeada ülkemizdeki en büyük ada olup, içerisinde beş adet tatlı su baraj göleti ve bir adet de tuzlu lagünü bulunmaktadır. P. parva örneğinin kaydedildiği Gökçeada rezervuarı 1977-1983 yılları arasında Büyükdere akarsuyu üzerine içme ve sulama amaçlı olarak kurulmuştur (DSI, 2016). Gökçeada'da kurulan Şahinkaya ve Dereköy rezervuarlarının 1981-1984 yılları arasında Cyprinus carpio (Linnaeus, 1758) ile balıklandırıldığı bilinmektedir (Ulutürk vd., 1996). Devlet Su 
İşleri 252. Şube Müdürlüğü'nden alınan bilgilere göre (T.C. Başbakanlık İletişim Merkezi (BiMER)'ne yapılan 1700119182 sayılı başvuru) Gökçeada Zeytinliköy Baraj Gölü(Gökçeada barajı)'ne 2004 yılında Aynalı Sazan balık yavrusu atılmıştır. Gökçeada'da mevcut baraj gölleri ve bu barajları besleyen tatısulardaki balık faunası hakkında detaylı bir bilgiye rastlanmamıştır. Adadaki akarsularda yapılan genel taramada, yaz mevsimi olması dolayısıyla birçok akarsuyun kuruması nedeniyle örnekleme yapılamamıştır. Gökçeada'da 08.06.2016 tarihinde yapılan arazi çalışmasında sadece Eşelek çayında C. carpio bireyine rastlanmıştır. Adada yapılan incelemede Gökçeada Zeytinliköy rezervuarında daha önce 0 bölgede kaydı bulunmayan $P$. parva istilacı türü bu çalışma ile ilk kez bildirilmektedir. Türkiye içsularının doğal balık faunası içerisinde yer almayan bu türün buraya balıklandırma yolu ile ulaştığı düşünülmektedir.

Tablo 1. P.parva örneklerinin metrik karakterleri $(\mathrm{mm})$ Table 1. Metric characters of $P$. parva specimens $(\mathrm{mm})$

\begin{tabular}{lll}
\hline Vücut ölçümleri & OrtıS.S. & Min-Max \\
\hline Total boy & - & $56,75-76,1$ \\
Standart boy (SB) & - & $46,25-62$ \\
$\begin{array}{l}\text { Vücut ölçümlerinin Standart } \\
\text { Boy’a oranları (\%SB) }\end{array}$ & \\
Maksimum vücut yüksekliği & $25,37 \pm 1,37$ & $24,52-26,96$ \\
Predorsal mesafe & $48,11 \pm 1,46$ & $45,36-50,27$ \\
Preanal mesafe & $70,54 \pm 3,49$ & $67,7-74,05$ \\
Prepelvik mesafe & $48,68 \pm 2,93$ & $46,17-51,89$ \\
Dorsal yüzgeç uzunluğu & $11,66 \pm 1,46$ & $10,05-12,91$ \\
Anal yüzgeç uzunluğu & $7,64 \pm 0,82$ & $6,7-8,23$ \\
Kuyruk sapı yüksekliği & $11,18 \pm 1,04$ & $10,05-12,11$ \\
Baş boyu & $21,28 \pm 0,24$ & $21,08-21,55$ \\
Baş yüksekliği & $15,49 \pm 0,67$ & $14,92-16,22$ \\
Baş genişliği ( Gözün arka & $13,08 \pm 1,71$ & $12,54-13,48$ \\
hizasından) & & \\
Baştaki ölçümlerinin Baş & & \\
boyuna (BB) oranları (\%BB) & & $29,74-31,09$ \\
Göz çapı & $29,91 \pm 1,10$ & $25,84-34,36$ \\
Burun uzunluğu & $31,22 \pm 4,68$ & $35,90-43,45$ \\
Gözler arası mesafe & $40,39 \pm 3,97$ & $59,49-62,55$ \\
Baş genişliği (Gözün arka & $61,46 \pm 1,71$ & \\
hizasından) & & \\
\hline
\end{tabular}

Ekmekçi ve Kırankaya (2006)'ya göre, $P$. parva türünün üreme kapasitesindeki yüksek başarısının bir sebebi, bu türün büyük popülasyonlar oluşturmasıdır. P.parva bulunduğu ortamda erken yaşta eşeysel olgunluğa erişmesi, üreme mevsimi boyunca birkaç defada nisbeten iri yumurtalar bırakması, erkeklerin yumurtalara bekçilik etmesi ve kısa yaşam döngüsü gibi özelliklerinin avantajı sonucunda Türkiye içsularına hızlı bir şekilde yayıldığı görülmektedir (Erk'akan 1984; Wildekamp vd., 1997; Küçük, 1997; Neer vd., 2000; Şaşı ve Balık 2003; Yılmaz vd., 2003; Ekmekçi ve Kırankaya 2006; Ekmekçi vd., 2013; Tarkan vd., 2015). Dal, yaprak, plastik atık gibi yerlere yumurtlayabilen $P$. parva, tehlikeli hastalık taşıması ve öteki türlerin yumurtaları ile yoğun bir şekilde beslenmesi sonucu ortamda bulunan doğal türler için olumsuz sonuçlar ortaya koymaktadır (Ekmekçi ve Kırankaya 2006). Bu çalışmada aynı bölgede başka bir balık türüne rastlanmamış olmakla birlikte baraj gölünde $C$. carpio türünün varlığı bilinmektedir. Adaya sazan ile balıklandırma esnasında P.parva'nın istenmeden taşındığı olasılığı çok güçlüdür. Bunun yanısıra $P$. parva türünün yumurta parazitliği ve hastalık etkeni Sphaerothecum destruens taşıması nedeniyle üzerinde önemle durulan bir istilacı balık türüdür (Gozlan vd., 2005, Ercan vd., 2015). P.parva'nın herhangi bir şekilde bir rezervuara taşındığında kolayca yerleşebildiği ve diğer sazangiller üzerinde taşıdığı parazitin yıkıcı etkisinin olabileceği bildirimektedir (Gozlan vd., 2005, Andreou ve Gozlan, 2016). Gökçeada tatısu balık faunasının bilinen tek tür olan C. carpio ile $P$. parva'nın ilişkisi ve bu ekonomik balık türü üzerindeki etkilerinin araştırıması önem taşımaktadır.

Ada Anadolu'dan izole olmuş bir ekosistem özelliğine sahip olmasından dolayı fauna ya da flora'daki değişimlerinin ve ekolojik değişimin izlenmesi açısından bir laboratuvar niteliğindedir. Ada koşulları ana kara koşullarına göre daha sınırıdır ve burada yaşayan canlıların bu zor koşullar altında ayakta durmaları zordur. P. parva türünün ada ekosistemi içinde yer almış olması ekolojik açıdan da ayrıca önemlidir. Bu nedenle adada tatlı su balık faunasının belirlenmesine yönelik daha detaylı mevsimsel çalışmaların yapılması ve istilacıların bu türler üzerindeki etkilerinin araştırıması gelecekte planlanmaktadır. $P$. parva'nın hastalık taşıııclığı göz önünde bulundurularak, özellikle ada tatısu balık popülasyonlarındaki enfeksiyonuna dair ve adada izole bir popülasyon oluşturacağından genetik çeşitliliği üzerine çalışmalar yapılması önerilir.

\section{TEŞEKKÜR}

Bu çalışma verileri TC Çevre ve Orman Bakanlığı Doğa Koruma ve Milli Parklar Genel Müdürlüğü tarafından desteklenen Çanakkale Ili Biyoçeşitilik Envanter Projesi kapsamında toplanmış̧ır. Arazi çalışmaları esnasında yardımlarını esirgemeyen Muhittin AKSAN'a teşekkürü borç biliriz.

\section{KAYNAKÇA}

Andreou, D. \& Gozlan, R.E. (2016). Associated disease risk from the introduced generalist pathogen Sphaerothecum destruens: management and policy implications. Parasitology, 143:1204-1210. doi: $10.1017 / S 003118201600072 X$

Atalay, M.A. \& Toslak, C. (2013). Balıklandırma, Yabancı ve İstilacı Balık Türleri ile İlgili Ulusal ve Uluslararası Mevzuat. İstanbul Üniversitesi Su Ürünleri Dergisi, 28:39-62. 
Banarescu, P.M. (1999). Gobio (Cuvier, 1816) In the Freshwater Fishes of Europe. Vol. 5/l: Cyprinidae 2/l (Banarescu, P.M., ed.), pp. 33-36. Wiebelsheim: Aula-Verlag.

Çetinkaya, O. (2006). Türkiye Sularına Aşılanan veya Stoklanan Egzotik ve Yerli Balık Türleri, Bunların Yetiştiricilik, Balıkçılık, Doğal Populasyonlar ve Sucul Ekosistemler Üzerindeki Etkileri Veri Tabanı İçin Bir Ön Çalışma. In: Emre Y, Diler I (eds), Balıklandırma ve Rezervuar Yönetimi Sempozyumu, T.K.B Akdeniz Su Ürünleri Araştırma, Üretim ve Eğitim Enstitüsü Yayınları, (pp 205-235). Antalya, Türkiye: Bildiriler Kitabı.

Çiçek E., Birecikligil S.S. \& Fricke R. (2015). Freshwater fishes of Turkey; a revised and updated annotated checklist. Biharean Biologists, 9(2):141157.

DSI, (2016). Gökçeada Barajı. Alıntılanma adresi: http://www2.dsi.gov.tr/baraj/detay.cfm?BarajID=83 (25.01.2017).

Ekmekçi, F.G. \& Kirankaya, S.G. (2006). Distribution of an invasive fish species, Pseudorasbora parva (Temminck \& Schlegel, 1846) in Turkey. Turkish Journal of Zoology, 30:329-334.

Ekmekçi, F.G., Kırankaya, Ş.G., Gençoğlu, L. \& Yoğurtçuoğlu, B. (2013). Türkiye İçsularındaki İstilacı Balıkların Güncel Durumu ve İstilanın Etkilerinin Değerlendirilmesi. Present Status Of invasive fishes in inland waters of Turkey and assessment of the effects of invasion. Journal of Fisheries and AquaticSciences, 28:105-140.

Ercan, D., Andreou, D., Sana, S., Öntaş, C., Baba, E., Top, N., Karakuş, U. Tarkan, A.S. \& Gozlan, R.E. (2015). Evidence of threat to European economy and biodiversity following introduction of an alien pathogen on the fungal-animal boundary. Emerging Microbes \& Infections, 4: e52. doi: 10.1038/emi.2015.52

Erk'akan, F. (1984). Trakya Bölgesinden Türkiye İçin Yeni Kayıt Olan Bir Balık Türü Pseudorasbora parva (Pisces Cyprinidae). Doğa Bilim Dergisi 8(3):350-356.

Freyhof, J., Ekmekçi, F.G., Ali, A., Khamees, A.R., Özuluğ, M., Hamidan, N., Küçük, F. \& Smith, K.G. (2014). The Status and Distribution of Freshwater Biodiversity in the Eastern Mediterranean. In: Smith, K.G., Barrois, V.,
Darwall, W.R.T., Numa, C. (Ed.). Freshwater fishes, (pp:19-42). Cambridge, UK, Malaga, Spain and Gland, Switzerland.

Gozlan, R.E., St-Hilaire, S., Feist, S.W., Martin, P. \& Kent, M.L. (2005). Biodiversity- Diseasethreatto Europeanfish. Nature, 435:1045-1046.

Kottelat, M. \& Freyhof, J. (2007). Handbook of European freshwater fishes. Kottelat, Cornol, Switzerland and Freyhof, Berlin, Germany.

Küçük, F. (1997). Antalya Körfezine Dökülen Akarsuların Balık Faunası ve Bazı Ekolojik Parametreleri Üzerine Bir Araştırma, Doktora Tezi, Süleyman Demirel Üniversitesi, Fen Bilimleri Enstitüsü, Su Ürünleri Mühendisliği Anabilim Dalı, Isparta, 138s

Neer, W.V., Wildekamp, R.H., Küçük, F., Ünlüsayın, M., Waelkens, M. \& Paulissen, E. (2000). Results of the 1996 Survey of the Fish Fauna of the Aksu River and Some Lakes in Southwestern Anatolia, and the Implications for Trade at Sagalasos, Sagalassos V, Report on the survey and excavation campaigns of 1996 and 1997, Leuven University Press, 833-845.

Polat, N., Zengin, M. \& Gümüş, A. (2011). İstilacı balık türleri ve hayat stratejileri. Karadeniz Fen Bilimleri Dergisi, 1(4):63-86.

Şaşı, H. \& Balık, S. (2003). The Distribution of Three Exotic Fishes in Anatolia, Tr. J. of Zoology, 27:319-322.

Tarkan, A.S., Marr, S.M. \& Ekmekçi, F.G. (2015). Non-native and translocated freshwater fish species in Turkey. FISHMED 2015.003:1-28.

Ulutürk, T., Yurder, G., Batır, H. \& Yazıcı, M. (1996). Gökçeada Göletlerinde Aynalı Sazan (Cyprinus carpio L.) Üretilmesi ile İlgili Araştırma. TUBITAK VHAG - 581 Kesin Rapor. 124s.

Wildekamp, R.H., Neer, W.V., Küçük, F. \& Ünlüsayın, M. (1997). First record of the eastern Asiatic gobionid fish Pseudospora parva from the Asiatic part of Turkey, Journal of Fish Biology, 51:858-861.

Yılmaz, F., Barlas, M., Özdemir, N. \& Yorulmaz, B. (2003). The Freshwater Fishes of Muğla (South-West, Turkey). International Symposium of Fisheries and Zoology, İstanbul, 287-292. 